\title{
The Rogue Poster-Children of Universal Design: Closed Captioning and Audio Description
}

\author{
John-Patrick Udo
}

Ryerson University

\section{Deborah I. Fels}

Ryerson University

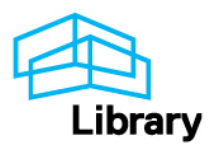




\begin{abstract}
To abide by the tenants of universal design theory, the design of a product or service needs to not only consider the inclusion of as many potential users and uses as possible but also do so from conception. Control over the creation and adaption of the design should, therefore, fall under the purview of the original designer. Closed captioning has always been touted as an excellent example of an design or electronic curb-cut because it is a system designed for people who are deaf or hard of hearing, yet is used by many others for access to television in noisy environments such as gyms or pubs, or to learn a second language. Audio description is poised to have a similar image. In this paper, we will demonstrate how the processes and practices associated within closed captioning and audio description, in their current form, violate some of the main principles of universal design and are thus not such good examples of it. In addition, we will introduce an alternative process and set of practices through which directors of television, film and live events are able to take control of closed captioning and audio description by integrating them into the production process. In doing so, we will demonstrate that closed captioning and audio description are worthy of directorial attention and creative input rather than being tacked on at the very end of the process and usually to only meet regulatory or legislative mandates.
\end{abstract}

\title{
Introduction
}

Closed captioning (CC) is the verbatim translation of spoken dialogue from television and film that is typically presented as white text on a black background and overlaid or scrolling on the original video on the screen. It is designed for access to television and film for people who are deaf or hard of hearing. CC has always been touted as the "electronic" poster-child of universal design because it is a system designed for people with disabilities, yet can be used by many others for access to television such as people in noisy gyms or pubs, or to learn a second language.

Audio description (AD) is a second audio track produced, in conjunction with the original audio track, to provide descriptions of important visual elements of a film or television show for access by people who are blind or low vision. It is also poised to be 
another "good" example of universal design because it can be used by the larger population.

While CC and AD are used to make media and live events more accessible to deaf and hard of hearing, and blind and low vision communities respectively, there has been little research reporting the nature of these strategies and effects of these services. As such, there is a lack of critical evaluation of these established processes and practices from a universal and engineering design standpoint.

To abide by the tenants of universal design theory, the design of a product or service needs to not only consider the inclusion of as many potential users and uses as possible but also do so from conception. Control over the creation and adaption of the design should, therefore, fall under the purview of the original designer. In this paper, we will demonstrate how the processes and practices associated within $\mathrm{CC}$ and $\mathrm{AD}$ in their current form, adhere to some but also violate many of the principles of universal design. In addition, we will introduce an alternative process and set of practices through which directors of television and film events are able to take control of CC and AD by considering them as an integral element through which their creative vision is communicated. While CC and AD are used for live events, we will limit the scope of this paper to discussing prerecorded material. In addition, much of the discussion here relates to $\mathrm{CC}$ and $\mathrm{AD}$ as it applies to North American broadcast processes, procedures and standards. European standards are different, however, the general approach to captioning and $\mathrm{AD}$ is remarkably similar. 


\section{Closed captioning (CC) and audio description (AD)}

$\mathrm{CC}$ is produced by recording the verbatim text of the dialogue and then synchronizing the timing, as close as possible with the timecode of that dialogue.

Phrasing and the number of lines that appear on the screen at any one time is governed by industry standards that have been developed to optimize readability by users. The two major global delivery standards consist of Line21 and teletext/subtitling; Vertical Blanking Interval (VBI) Line21, known as CC, being the analogue standard for North America or NTSC systems as defined by EIA-608 (Abrahamian, 2003); and teletext being for European or PAL systems. In this paper, we will focus on CC.

Government legislation in many western countries specifies the quantity of captioning required for broadcast stations. For example, in Canada, the Canadian Radio, Television and Telecommunications Commissions (CRTC) requires that all television broadcasters must offer CC for 100\% of all programming (although this does not include advertising) (CRTC, 2007).

In its current form for analogue or digital television, the appearance of $\mathrm{CC}$ is limited to a small set of fonts, colours and graphics (Canadian Association of Broadcasters, 2004). Initially, limitations in decoder technology of the 1970's and 80 's posed legibility problems so that captions were restricted to upper case letters, using a white monospaced font and a black background (Canadian Association of Broadcasters, 2004). Advancements in encoder and decoder technologies now allow for legible mixed case letters, multiple fonts and colours, and numerous symbols (Canadian Association of Broadcasters, 2004). However, despite the new capabilities, the uppercase white text on 
black background (shown in Figure 1) is still the most common format recommended by the captioning standards and used for television captioning.

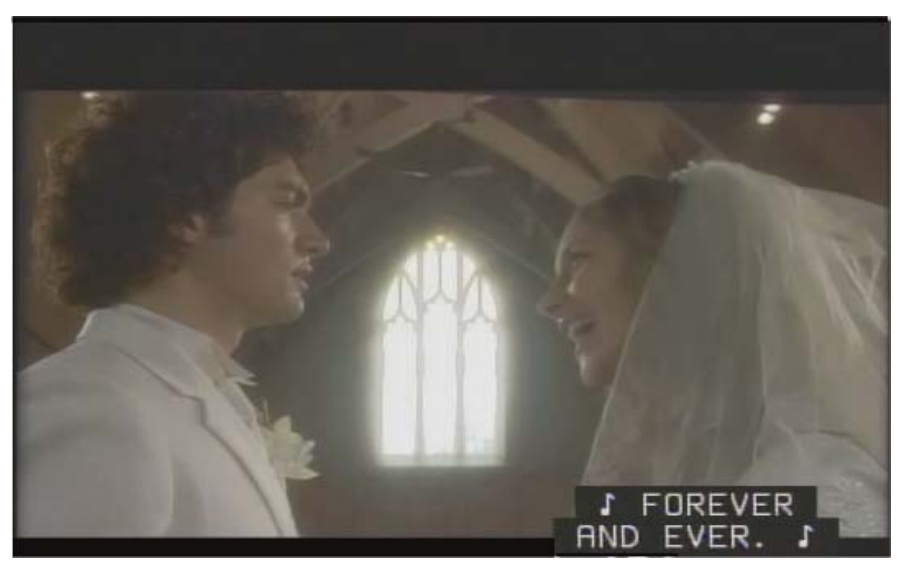

Figure 1: Example of conventional closed captions.

Video description is a relatively new access technology compared with CC; however, people who are blind have had the benefit of description for many, many years. It was in the form of descriptions of events happening around the person who was blind and provided by family, and friends.

The formal version of video description where procedures and processes are defined so that others could provide description for media and cultural events was originally formalized in the 1970s by G. Frazier (Snyder, 2004). Most of the guidelines available recommend that descriptions be factual and purposely void of emotionally subjective interpretation. Descriptions should provide an audio account of the visual information important to the narrative (WGBH, 2006) that include relevant visual action imparted by an actor's body language, unspoken acting, scene changes, facial expressions, costumes and other visual aspects and inserting them within the natural 
pauses in the dialogue (WGBH, 2006; CRTC, 2004; Media, 2003; Wall, 2002). They are carefully timed so that they do not interfere with the dialogue or program narration. The description track is then mixed with the main program audio and broadcast on the secondary audio track (SAP).

\section{Universal Design}

Universal design theory consists of two main goals: 1) a "user population" and the "potential uses" of designs must be very broadly defined and include a variety of users and user abilities that would be inclusive of as many different people as possible including those this disabilities (Rose \& Meyer, 2002); and 2) designers make these considerations at the conception and specification phases of design rather than as a retrofit after all else is completed (Stephanidis, 2001). Designs which satisfy these two goals are often termed "curb cuts" because the sidewalk curb cut is one of the best examples of universal design.

Perceived as costly and catering to the needs of a very small and specific populations, universal design theory is often discounted as a viable and practical alternative to conventional design practices (Stephanidis, 2001). Standards, guidelines and legislation/regulations such as ADA section 508 (U.S. Dept of Justice, 2003) and Accessibility for Ontarians with Disabilities Act, and W3C Web Accessibility Guidelines (2003), are thus in place to encourage consideration of a universal design approach. However, the goals are often thwarted by designers who work to remain in compliance with only specific legislative requirements or guidelines because this often results in limited or incomplete designs and solutions. 
In addition, if conventional design approaches are used, access for people with disabilities becomes an afterthought and an expensive retrofit. Emiliani \& Stephanidis (2000) suggest that retrofitting is problematic because 1) adaptations can be incompatible with rapid technological change; 2) not all technology can be adapted without a loss of functionality in the original design; and 3) adaptations can be programming-intensive, costly, and difficult to implement and maintain.

\section{How do CC and AD adhere and stray from the Principles of Universal Design?}

Connell et al. (1997) outline seven principles of universal design: equitable use; flexibility in use; simple and intuitive to use; perceptible information; tolerance for error; low physical effort; and size and space for approach and use. We present these guidelines as a means of assessing the appropriateness and validity of $\mathrm{CC}$ and $\mathrm{AD}$ as prime examples of universal design.

\section{Principle One: Equitable Use}

"The design is useful and marketable to people with diverse abilities"

$$
\text { Connell et al., 1997, p. } 34
$$

Guidelines for this principal suggest that whenever possible, all users should be given the same means to use a product or service. If this is not possible, users should be given an equivalent opportunity for use. No users should be stigmatized or segregated when compared to their peers or that their safety, security or privacy is compromised due to inaccessible designs. Regardless of ability, all users should find the design appealing to use (Connell et al., 1997). 
$\mathrm{CC}$ and $\mathrm{AD}$ abide by these guidelines in several important ways, as they are useful tools for individuals with and without disabilities. These tools provide individuals who are vision or hearing impaired independent access to information and entertainment that would otherwise be inaccessible without the help of a sighted or hearing peer acting as an interpreter. Alone or with an able-bodied peer, individuals with hearing or vision impairments have the option of using $\mathrm{CC}$ and $\mathrm{AD}$ to improve their understanding while, at the same time, doing so in a manner that does not detract from that of an able-bodied peer.

In addition, $\mathrm{CC}$ has proven to be beneficial to individuals who are learning a new language (Guillory, 1998; Shea, 2000; Stewart \& Pertusa. 2004) can improve reading skills (Goldman \& Goldman, 1988; Linebarger, 2001). Hearing users can also benefit from captions if they are unable to access audio such as at a gym or bar, or where using audio may further pollute the sound environment, such as in an office. Similarly, AD is useful for sighted individuals who are unable to devote their complete visual attention to watching entertainment media because their visual attention is elsewhere (such as sewing or ironing) or they must constantly leave and re-enter a room that is within ear-shot (doing the laundry, cooking). Studies have also shown the benefit of AD for individuals who are have learning disabilities or are elderly (Watkins \& Charlson, 2002). Researchers are also exploring how AD scripts (Turner \& Colinet, 2004) and CC text (Flieschman \& Roy, 2007) can be used to index video.

In much of the research carried out for $\mathrm{AD}$ and $\mathrm{CC}$, entertainment and enjoyment are secondary factors to comprehension. For example, Pettitt, Sharpe, \& Cooper (1996) and Schmeidler \& Kirchner (2001) compared participant enjoyment and performance 
measures with content containing AD to content without it. However, Peli \& Fine (1996) examined participant comprehension through multiple choice questions with sighted and low vision viewers after watching segments of two documentaries. Harkins et al. (1995) examined viewer preferences but again did not consider enjoyment factors for CC. Jensema (1998) assessed participant reading speed for CC but did not evaluate enjoyment. As the primary purpose of watching television and films is for entertainment (Bordwell \& Thompson, 2001), measures of entertainment and enjoyment should be key factors in studying the impact of $\mathrm{CC}$ and $\mathrm{AD}$ on audiences.

The marketability of $\mathrm{CC}$ and $\mathrm{AD}$ is also problematic. Currently, $\mathrm{CC}$ and $\mathrm{AD}$ are considered "cost" services which broadcasters must provide in order to comply with governmental and broadcast mandates (e.g. CRTC, 2004; Media Access Australia, 2007, FCC, 2003, ITC, 2000). In order to reduce costs, a constant concern of broadcasters, CC and $\mathrm{AD}$ are often farmed out to third party accessibility vendors who are responsible for creating $\mathrm{CC}$ and/or $\mathrm{AD}$ for a particular show and are often given little time or funding to do so. Some broadcasters and production studios create their own CC and AD in-house, yet similar constraints exist. In an effort to reduce the costs of AD, Vera (2006) has suggested that the translator or subtitler could also create AD, citing their familiarity with the content as a way to decrease turnover time and lower costs.

$\mathrm{CC}$ and $\mathrm{AD}$ are seldom created as part of the production process, let alone overseen by members of the original creative team. As such, third party vendors follow very specific guidelines (such as those provided by the Canadian Association of Broadcasters, 2004) which dictate how and what is interpreted/translated, a formula that is applied with very little variation regardless of genre or audience. CC guidelines and 
standards dictate the font type, size and case of font, as well as caption placement and timing (ITC, 1999). Similarly, AD guidelines and standards emphasize the importance of prioritizing information, anticipating action and relaying information objectively (ITC, 2000).

Government and/or broadcasting mandates ensure that $\mathrm{CC}$ and $\mathrm{AD}$ exist as accessibility strategies so that hearing and vision impaired spectators are able to access entertainment media. As such, these accessibility strategies have not had to withstand the demands of the market, since adoption rates for these services are not linked to an increase or decrease in profits. Whereas ratings are indicative of the price point at which commercial advertisement space can be sold, the number of people who use CC and AD services does not increase or decrease financial revenue. Hence, there is no financial incentive to make current $\mathrm{AD}$ and $\mathrm{CC}$ services more desirable or increase their marketability because the current business model that exists considers them only as a cost and not as a potential revenue source. Innovation is, therefore, thwarted, since broadcasters are unlikely to financially contribute to a venture from which they will see no financial benefit.

For example, practices and processes associated with $\mathrm{CC}$ have not changed within the past 30 years. The purpose of uppercase lettering was related to the inability of North American Line21 television technology in the 1970s to display descending characters such as "g" and "y" However, television technology has made considerable advances since that time so that descending characters can be accurately displayed while captioning practices remain essentially the same even though, for example, there is ample evidence (reference) showing that the mixed case fonts are easier to read. 


\section{Principal Two: Flexibility in Use}

"The design accommodates a wide range of individual preference and abilities"

Connell et al., 1997, p. 34

Guidelines stress the importance of giving users choice as to how they access a product or service. In addition, users should be able to precisely and accurately use a product by adjusting its many adaptable features to suit their needs, including the ability to work at their own pace (Connell et al., 1997). The service or product should not require any additional adaptation to be useable (Erlandson, 2007).

Individuals with vision and hearing impairments are often cited as the primary users of $\mathrm{CC}$ and $\mathrm{AD}$. However, we argue that the primary user is actually much more covert: the broadcaster and media producer, who use these services as a means of placating governmental requirements. Broadcasters and producers have one very specific need and preference: to provide $\mathrm{CC}$ and $\mathrm{AD}$ and to do so incurring little cost. This need and preference are given priority over all others, since broadcasters and producers control the amount of funding and length of time that accessibility service vendors are given to create $\mathrm{CC}$ and $\mathrm{AD}$. In addition, there is immense pressure on service vendors to offer the fastest turnaround for the lowest price. Quality is, therefore, sacrificed in order to meet the needs and preferences of the financier of the service, not the individual who uses the service to enjoy entertainment media.

Satisfying the needs and preferences of the secondary user, the individual who is vision or hearing impaired, is much more complicated and difficult to address. For CC, research on viewer attitudes towards current caption quality does exist (see Harkins et al., 1995; Jordan, 2003). For AD, significantly less academic literature exists on spectator 
preferences (see Packer \& Kirchner, 1997). Regardless of what viewers have said, they are unable to customize the $\mathrm{CC}$ and $\mathrm{AD}$ offered in any way.

The process for making a television and film accessible varies depending upon the user population being considered. For $\mathrm{CC}$ and $\mathrm{AD}$, it begins with the broadcaster sending a copy of the master tape to a third party accessibility vendor or to its in-house service. For AD, a team of individuals, often consisting of a describer and an audio production expert, creates a description script, records and edits the description track balancing for volume levels and timing, mixes it with the main program audio and then submits it to the production studio or broadcaster (WGBH, b). For CC, often an electronic script is available to the captionist who is responsible for adding, subtracting and adapting information so that viewers understand what is occurring onscreen The caption data is then encoded onto the program's video (WGBH, a) and returned to the broadcaster or production studio. Most AD and CC service providers have some quality control mechanism in place. Although several studios create produce their own $\mathrm{CC}$ and $\mathrm{AD}$, captionists and describers seldom interact or receive any form of guidance from the director.

Strategies for the incorporation of $\mathrm{CC}$ and $\mathrm{AD}$ into the actual production are extremely rare. Accessibility is not built into the overall production of entertainment media, for directors do not oversee or even approve of CC and AD. We believe that the absence of the director within this process demonstrates perhaps the most egregious turn from universal design theory. 


\section{Principal Three: Simple and Intuitive Use}

"Use of design is easy to understand, regardless of user's experience, knowledge, language skills, or current concentration level"

Connell et al., 1997, p. 34

Guidelines recommend that designs align with the expectations and intuition of users, information should be arranged by importance, accommodate individuals with low literacy and language skills as well as prompt the user before the task and provide feedback before and after the task is completed (Connell et al., 1997). Knowledge should be built into designs to reduce complexity (Erlandson, 2007).

Once activated, $\mathrm{AD}$ and $\mathrm{CC}$ are relatively easy to use. However, many of the steps leading to activation and the subsequent deactivation of these services are problematic. The acquisition of entertainment media or attendance at entertainment experiences is often the first and largest barrier encountered. This barrier is made up of many logistical and technical "curbs" that have yet to be "cut". For example, logistical curbs include finding a cinema that is playing a movie with $\mathrm{AD}$ and/or $\mathrm{CC}$ while technical curbs encompass activation, use and deactivation. We have outlined the many technical and logistic curbs which ace $\mathrm{CC}$ and $\mathrm{AD}$ users when attending the cinema (see Table 1) and watching entertainment media at home (see Table 2). While several solutions currently exist, many are difficult or inconvenient to use. 
Table 1: Issues with simple and intuitive use at the cinema

\begin{tabular}{|c|c|c|c|}
\hline Curb/Issue & Group Effected & Solution(s) & Problems with solution \\
\hline \multirow{5}{*}{$\begin{array}{l}\text { Locate a cinema } \\
\text { playing desired } \\
\text { movie with } \\
\text { accessibility } \\
\text { service }\end{array}$} & \multirow{3}{*}{ Blind or Low vision } & $\begin{array}{l}\text { Ask friend/family member to } \\
\text { check newspaper }\end{array}$ & Dependence on others \\
\hline & & $\begin{array}{l}\text { Call talking movie listing } \\
\text { service (e.g., movie phone) }\end{array}$ & Information may not be included \\
\hline & & $\begin{array}{l}\text { Call theatre directly, speak to } \\
\text { theatre staff }\end{array}$ & $\begin{array}{l}\text { Theatre staff may be untrained and unaware } \\
\text { of accessible services offered by theatre. }\end{array}$ \\
\hline & \multirow[t]{2}{*}{ Hard of Hearing or Deaf } & Search online & $\begin{array}{l}\text { Information not always available, accurate } \\
\text { or updated. }\end{array}$ \\
\hline & & Use newspaper or internet & $\begin{array}{l}\text { Information not always available, accurate } \\
\text { or updated. }\end{array}$ \\
\hline \multirow{3}{*}{$\begin{array}{l}\text { Ensure that the } \\
\text { theatre actually } \\
\text { owns the } \\
\text { necessary } \\
\text { equipment and } \\
\text { that it is clean } \\
\text { and functional. }\end{array}$} & Hard of Hearing or Deaf & $\begin{array}{l}\text { Use TTY or relay service to call } \\
\text { theatre directly, speak to theatre } \\
\text { staff }\end{array}$ & $\begin{array}{l}\text { Theatre staff may be untrained and } \\
\text { inexperienced with TTY or TTY is not } \\
\text { available. }\end{array}$ \\
\hline & \multirow{2}{*}{$\begin{array}{l}\text { Blind or Low Vision \& } \\
\text { Hard of Hearing or Deaf }\end{array}$} & $\begin{array}{l}\text { Call theatre directly, talk to staff } \\
\text { using appropriate assistive } \\
\text { technology (e.g., TTY or relay } \\
\text { service). }\end{array}$ & $\begin{array}{l}\text { Theatre staff may assume that if a service is } \\
\text { advertized it must be available, functional } \\
\text { and clean. }\end{array}$ \\
\hline & & Attend movie & $\begin{array}{l}\text { Potential disappointment. Service may not } \\
\text { be offered or the equipment necessary may } \\
\text { be unavailable, inoperable or unclean. }\end{array}$ \\
\hline
\end{tabular}


Table 2: Issues with simple and intuitive at home

\begin{tabular}{|c|c|c|c|}
\hline Issue/Curb & Group Effected & Solution(s) Available & Problems with solution \\
\hline \multirow{2}{*}{$\begin{array}{l}\text { Television or Video On } \\
\text { Demand Schedule } \\
\text { inaccessible }\end{array}$} & \multirow[b]{2}{*}{ Blind and Low Vision } & $\begin{array}{l}\text { Use screen reader to access } \\
\text { internet based listings }\end{array}$ & $\begin{array}{l}\text { Requires computer and internet access. } \\
\text { Lack of choice. }\end{array}$ \\
\hline & & $\begin{array}{l}\text { Ask family or friend to find } \\
\text { selected media or read } \\
\text { schedule aloud. }\end{array}$ & $\begin{array}{l}\text { Inconvenient for all. Dependence on } \\
\text { others. Lack of choice. }\end{array}$ \\
\hline \multirow{4}{*}{$\begin{array}{l}\text { Activating/Deactivating } \\
\text { Service }\end{array}$} & \multirow{3}{*}{ Blind and Low Vision } & Ask family or friend to assist & $\begin{array}{l}\text { Information unavailable or hard to find. } \\
\text { Takes time and effort Dependence on } \\
\text { others. }\end{array}$ \\
\hline & & Trial and Error & Takes time and effort. \\
\hline & & $\begin{array}{l}\text { Remember layout of remote } \\
\text { and where SAP button/menu } \\
\text { is located and what buttons to } \\
\text { press to activate it }\end{array}$ & $\begin{array}{l}\text { User does not receive feedback until task } \\
\text { is completed. User has to remember } \\
\text { visual cues and his/her response. }\end{array}$ \\
\hline & $\begin{array}{l}\text { Hard of Hearing and } \\
\text { Deaf }\end{array}$ & $\begin{array}{l}\text { Remember and go through a } \\
\text { series of steps to access } \\
\text { captions }\end{array}$ & Takes time, not intuitive. \\
\hline \multirow{4}{*}{$\begin{array}{l}\text { Using DVD, PVR, } \\
\text { VHS menus }\end{array}$} & \multirow{4}{*}{ Blind and Low Vision } & $\begin{array}{l}\text { Ask family or friend to } \\
\text { control DVD, PVR or VHS. }\end{array}$ & $\begin{array}{l}\text { Inconvenient for all. Dependence on } \\
\text { others. Lack of choice. }\end{array}$ \\
\hline & & & \\
\hline & & $\begin{array}{l}\text { Remember layout of menu } \\
\text { and remote }\end{array}$ & Non-Intuitive, requires concentration. \\
\hline & & Use specially adapted remote & Expensive and specialized device. \\
\hline
\end{tabular}

\section{Principle Four: Perceptible information}

"The design communicates necessary information effectively to the user, regardless of ambient conditions or the user's sensory abilities"

Connell et al., 1997, p. 34

Guidelines include that the designer should use different modes to disseminate essential information redundantly and legibly. Design should ensure compatibility with devices and processes meant to be used by people with disabilities.

Director's understanding of effective communication

When creating a feature film or television program, a director needs to realize the advantages and disadvantages of her medium and modify his message to reflect this 
awareness. She controls the creation of an entertainment experience, responsible for laying and juxtaposing the use of cinematic conventions (such as costumes, lighting, and acting style) in an effort to manipulate viewer response (Bordwell \& Thompson, 2001; Branigan, 1984). She is responsible for ensuring the film, as a whole, accurately and effectively communicates her vision, as she is the designer of the experience. As such, the director must consider how her target demographic will respond to the stimuli she presents and decide whether she wishes to play towards or against these expectations. The audience may or may not understand or appreciate the director's intended meaning and, even if they do, may not find it enjoyable. This factors into enjoyment of the entertainment experience, not the effectiveness of the director's communication.

Effectively communicating an entertainment experience means that each of the parts come together to form the whole, an experience greater than any one piece. While an audience member may not realize the effect that each piece has on their overall experience, the director considers how each of these cinematic conventions can be used to manipulate spectators to experience a specific emotional response (Bordwell \& Thompson, 2001). For example dialogue, music, sound effects, pitch, tone and speech prosody are combined to communicate some of the meaning and emotion of the content through sound while images and graphics are used to convey meaning and emotion that balance or counterbalance the sound.

Captionist and describer's understanding of effective communication

Captionists focus on the verbatim translation of dialogue, occasionally supplying abbreviated information about music and sound effects. However, directors use music 
and non-dialogue sound to communicate as well and the absence of this sound stimuli represents an incomplete communication process (Ribrant1999; Goldberg 2000)

Audio Description Associates (n.d.) and the National Center for Accessible Media (2003) provide a very thorough description of the guidelines and conventions for AD for live and post-production content. Independent Television Commission (ITC, 2000) defines the criteria that are used to assess quality for AD: "There are three golden rules to description: describe what is there, do not give a personal version of what is there and never talk over dialogue or commentary" (p. 9). When AD is assessed, the "golden rules" are rarely questioned, nor the focus on the creation of an equal experience rather than an entertaining one. Interestingly, many of these guidelines highlight the complexity of the narrative presentation and the intended effect that the director, as the original designer, has worked to create (Braun, 2007; Vera, 2006). Yet, few recognize how the describer, as an outsider with little knowledge of the directors intentions, is unequipped to accurately reflect and represent these ideas and effect.

Audio describers realize that it is impossible to describe everything regardless of its importance and that they are creating an interpretation based on their understanding and some abstract guidelines. Captioning is mostly verbatim dialogue and there is little recognition that other audio stimuli are important for the effective communication of the director's vision. Regardless, more attention must be paid to how $\mathrm{CC}$ and AD alter and influence the messages of the original designer.

\section{Principle Five: Tolerance for error}

"The design minimizes hazards and the adverse consequences of accidental or unintended actions." 
Connell et al., 1997, p. 35

Connell et al. (1997) suggests that fail safe features and warnings of hazards or errors should be provided in order to assist in meeting this principle. In the context of CC and $\mathrm{AD}$, minimizing adverse consequences or unintended actions relates to issues resulting from miscommunication and error contained in the $\mathrm{CC}$ or $\mathrm{AD}$. Adverse consequences of errors in $\mathrm{CC}$ or $\mathrm{AD}$ could range from misunderstanding or misinterpretation of the content so that an individual might be embarrassed about participating in group discussions to poor performance in an educational context that depends on learning information presented in video content to missing or misunderstanding emergency information delivered through television media potentially having catastrophic consequences for the viewer.

During broadcast it is difficult to provide immediate remediation for errors or inaccuracies in $\mathrm{CC}$ or $\mathrm{AD}$. There is also little opportunity for viewers to provide feedback and have that feedback acknowledged by the broadcaster to make corrections in future broadcasts. As the third party service providers are often providing the $\mathrm{CC}$ or $\mathrm{AD}$, the director and broadcaster (or cinema) must rely on the quality control mechanisms put in place by that provider. If the director does not view the AD or CC work, then not only is a step missing from the quality control process but also the work is published without director consent.

In countries that depend on legislation or regulation for $\mathrm{CC}$ or $\mathrm{AD}$, viewers must often take legal action in order to effect change. Not only is this a costly approach that is out of reach of most viewers but also it cannot be carried out in a timely fashion, often taking years to resolve. 
Determining which service or individual provided the $\mathrm{CC}$ or $\mathrm{AD}$ can also be difficult as it is not always available as part of the credits or content. Fail safe mechanisms in the production and delivery of $\mathrm{CC}$ and $\mathrm{AD}$ must rely on quality control mechanisms put in place by broadcasters and service providers who do not necessarily have the time or funds to do so.

One mechanism that is available to ensure that $\mathrm{CC}$ and $\mathrm{AD}$ are broadcast at the broadcaster site is a constant monitoring of all feeds including $\mathrm{CC}$ and $\mathrm{AD}$ tracks. In addition, there are backup copies served by digital servers and redundancy in the broadcaster's system so that if there is a broadcast error, a backup copy can be immediately mounted.

\section{Principle Six: Low physical effort}

"The design can be used efficiently and comfortably, with a minimum of fatigue."

$$
\text { Connell et al., 1997, p } 35
$$

This principle applies to the physical ergonomic principle of maintaining an appropriate body posture and reducing sustained force or repetitive actions required to accomplish a task or interact with a design. This reduces the strain on the physical system that can cause fatigue and injury.

From a physical perspective, this principle does not apply to the consumption of accessible media. There are many different types of physical setups and displays that can be used for viewing and interacting with media including televisions and computer monitors. This principle would apply to the design and setup of these devices within a viewer's physical environment. 
The cognitive effort required to use the design efficiently, comfortably and with a minimum of fatigue could be considered as an addendum to this principle. We suggest that cognitive effort is exerted when the $\mathrm{AD}$ or $\mathrm{CC}$ contains errors such as spelling or timing errors, inaccurate or incorrect information, is incomplete or believed to be untruthful. Hewes et al., (1989) suggest that cognitive effort increases as people expend effort in deriving meaning from information. The more credible the source the less effort is expended, the less veracious the information is believed to be, the more cognitive effort is spent on ways to gather additional information to validate the accuracy of it. Brosius, Donsbach \& Birk (1996) found that viewers are able to learn and comprehend news information when the news text (in verbal or written form) corresponds directly with the visual images compared with images that are either divergent to the story or not relevant but still related to the story. Where there is either divergence between the text and image or where the images are simply standard news images that relate to the story but do not correspond directly to it, viewers do not perform as well on recall and comprehension measures as when the text and images are complementary. Brosius, Donsbach \& Birk suggest that several possible information and cognitive processes may influence this effect: 1) when images and text do not correspond, it is a distraction and people cannot focus on what is important; 2) when text and images correspond, they trigger cognitive retrieval mechanisms that are complimentary (corresponding images act as retrieval cues for stored text data); and 3) images which do not add any relevant information to the text are ignored but when images add information they are attended to and can thus easier to remember/process in the cognitive system. Unfortunately, there are very few studies which examine these issues with non-news programming such as drama or mysteries or 
with individuals who use $\mathrm{CC}$ relying mostly on visual information or who use $\mathrm{AD}$ where content presentation is mostly audio. We can speculate that when redundancy is limited because of the reduction in the types of media used, as is the case for CC and AD, the information processing requirements on the audience is higher. Introducing errors or ways in which the assistive technology does not correspond to the original image or audio track, such as missed words, timing errors, etc, will result in misunderstandings and reduced comprehension, inefficiencies increasing cognitive load potentially resulting in fatigue and decreased enjoyment.

\section{Principle Seven: Size and space for approach and use}

"Appropriate size and space for approach, reach, manipulation, and use regardless of body size, posture or mobility"

Connell et al., 1997, p 35

As in principle six, principle seven is aimed at accommodating physical differences and different body sizes and positions so as not to cause injury to the human physical system. This includes line of sight in a seated or standing position, keeping controls and displays within an arms-length reach, torso bending positions and hand or grip size for a general population (Helander, 2005) and for specialized populations such as people with disabilities (Kroemer, 2006).

Again, this does not specifically apply to CC or AD because they are not physical entities. For the physical setting in which viewers consume media (e.g., theatre, at home, and in public settings), this principle would apply directly. CC occupies a physical space on a screen. Standards such as the Canadian Association of Broadcasters, Closed Captioning Standards and Protocol for Canadian English Language Broadcasters (2004), 
address positioning issues of captions within the video document. With respect to physical on-screen location, the CAB (2004) standard recommends:

"1. Use one- or two-line captions placed just above or below the essential visual element.

2. Move the captions to the top or bottom of the screen if there is no essential visual element there.

3. Pop-on captions may be moved to any location on the screen, using three lines if necessary. They should be centre justified or left justified, never right justified.

4. If spoken words or lyrics are different from a textual graphic (for example, when there is talking over end credits), full captions must be included and moved using one of the techniques, pop-on or rollup (sic), so as to interfere as little as possible with the essential visual elements.

5. In the case of an extreme close-up of a person, do not cover the person's mouth with captions because many caption consumers speech read along with reading the captions." (p. 5)

$\mathrm{AD}$ is an audio signal that has no physical spatial component. However, we could extend this principle to include quality control settings such as volume levels, and pace. Viewers should be able customize these settings to their own comfort level and preferences.

\section{A new strategy}

A director considers how every aspect of a production factors into an audience's enjoyment of an entertainment experience, often making several minor variations between takes to ensure that her vision is captured on film. She works with her creative team to strategically use cinematic conventions to articulate this vision. The result is a collaboration which is unified through directorial control (Benedetti, 1985). For example, the costume designer would not be asked to develop, create, and execute costume design independently without the supervision and guidance from the director. If he did, the costume designs would be the interpretation of the designer and may not fit with the 
director's vision of them. At best, it would be reasonable approximation; at worst, it would be totally unacceptable. This is a clear example of how the director must oversee all aspects of the interpretation to ensure there is a cohesive implementation of her vision. The addition of $\mathrm{CC}$ and $\mathrm{AD}$ affects an audience's interpretation of this vision. Hence, we ask: why is it deemed acceptable for a third party, such as a describer or captionist, to independently attempt to convey a director's vision or interpretation of a piece of content?

It is the role of a director to present a coherent vision to his audience; she designs the entertainment experience (Ball, 1984). We suggest that $\mathrm{CC}$ and $\mathrm{AD}$ are two of the many creative components that comprise the whole entertainment package and are not separate entities. As such, the director and her creative team should determine how CC and $\mathrm{AD}$ can best be used to create an entertaining and enjoyable entertainment experience for viewers. The creative team knows best what aspects of their production are essential to the attainment of an entertainment experience that is rewarding and enjoyable. This means giving the director the artistic freedom to implement a CC or AD strategy that fits her overall vision. We suggest that this fits better with the principles of universal design because it abides by its two main tenets: 1) designed at the beginning of the process rather than "after-the-fact" and 2) designer of the product is involved and actually drives the process.

The director produces creative content with the goal of stimulating her audience to achieve a specific and, often pre-indentified, emotional reaction. For example, an individual who rents a horror film, whether blind, sighted, or deaf, does so with the express intention of being entertained. Within the context of a horror film, entertainment 
may be defined by degree to which spectators are scared by what is presented or, in some cases, amused by the director's attempts to manipulate audience experience into achieving this reaction. We believe that $\mathrm{CC}$ and $\mathrm{AD}$ practices misinterpret the principal of equitable use by defining what is presented by the director as information rather than stimuli.

Current $\mathrm{CC}$ and $\mathrm{AD}$ practices hold that equal access to the aural and visual information makes for equitable use. However, when a director plays eerie music as a character veers from the group to explore a dungeon on his own, she does so with the goal of stimulating her audience, not informing them. The $\mathrm{CC}$ user is given access to extremely basic information ( $\delta$ Eerie music $\delta$ ) so that the audio stimuli can be translated into text. Clearly, there is a large difference between knowing that eerie music is playing and experiencing the eerie music. By giving content creators control over the implementation of $\mathrm{CC}$ and $\mathrm{AD}$, access to an alternative stimulus that allows for an equivalent emotional response to that of a sighted or hearing user may be possible. Some directors have already experimented with this approach in CC implementations, using static emoticons (see Fels et al., 2005a) and animated captions (see Lee, Udo \& Fels; Rashid et al., 2007); and using first person AD (see Fels et al., 2005b). Other directors may choose different strategies to realize their vision. For example, decisions in AD could include determining whether the AD is open or closed, neutral or subjective, highly stylized or conventional. For CC, decisions might include whether or not to vary font type, size and colour or include animation.

Much like any other aspect of a television or film production, the director needs to have an overview of each area she supervises, but not an in-depth understanding of its 
inner workings (Benedetti, 1985). This role is left to the director of that area. For example, the director works with the lighting director to develop a lighting strategy that fits her overall vision of a scene. The director needs to understand the basics of how lighting is technically achieved as well as its constraints, yet relies mostly on the ingenuity of the lighting director to assess the feasibility of her requests as well as provide alternatives. We assert that audio describers and captionists should operate under a similar system, reporting to or, at least, consulting with a director of accessibility services. This team would then meet with the production's director to develop an accessibility strategy that re-interprets the "look and feel" of the production. The captioning and description team would then work together to develop prototypes that would, in turn, be approved by the director before being produced. The final product should receive similar attention.

While user feedback from cast, crew, describer and audience is essential to understanding how the accessibility features affect the enjoyment of performances, we believe that content creators should have the opportunity to creatively challenge viewers. To present the director with stringent guidelines or rules that must be obeyed for fear of displeasing the spectator infringes upon her right as an artist. Directors have the artistic license to create an end product which represents their own unique vision and, we believe, this should extend to the creation of $\mathrm{CC}$ and $\mathrm{AD}$. It is up to these individuals to determine what aspects of their production need to be communicated and how best to communicate these aspects to individuals who use $\mathrm{CC}$ and $\mathrm{AD}$. Whether or not an individual is actually entertained by what is presented is dependent on the individual's preference for style, story, and method of presentation. Hence, directors should have the 
opportunity to make an informed decision as to whether their $\mathrm{CC}$ and $\mathrm{AD}$ will stray from conventions, much like any other aspect under directorial control. It may be more appropriate to offer guidance in the form of suggestions rather than the "golden rules", an approach which Pfanstiehl \& Pfanstiehl advocate (The Play's the Thing, 1985). This process would give directors the flexibility of use that principle two advocates by allowing them to make creative choices that do not sacrifice the dissemination of their intended message.

There is some research that has been carried out to support the premise of director involvement. Fels et al. (2005a), Rashid et al. (2007) and Lee, Fels \& Udo (2007) worked with members of the television broadcast industries to create $\mathrm{CC}$ strategies that were reflective of the creative team's intent. Researchers facilitated the creation of CC strategies by providing members of the content creation team with an introduction and overview of current research on $\mathrm{CC}$ as well as the basic principles of universal design theory. Together, they decided that the director and script writer should oversee and participate in the development, creation and execution of the $\mathrm{CC}$, ensuring that the captions not only translated dialog but the emotions which were apparent in the way it was delivered. In working with these content creators, they found that some of the artistic choices made by the directors tended to go against our initial assessment of the director's intent. For example, the captionist(s) thought that the director was trying to convey a character's sadness in a song when, in fact, it was fear. We posit that the adoption of this alternative process may enable $\mathrm{AD}$ and $\mathrm{CC}$ to better adhere to principle five by reducing the amount of errors made by captionists and describers. 
Fels et al. (2005b \& 2006) used a similar creation process for an alternative AD strategy for an animated adult sitcom called "Odd Job Jack" which is shown on the Comedy Network. The script writer, director and sound team were involved in creating and producing the $\mathrm{AD}$. The creative team decided that a first-person narrative approach would be the best way to convey the visual comedy that was presented onscreen. Researchers found that blind and low vision users find the alternative approach less informative, yet more entertaining. Further research could indicate a need to redefine equitable use within the context of the entertainment experience.

Using similar content, Konstantinidis et al.'s (in press) market study assessed the feasibility of offering downloadable audio only episodes of television shows which included AD created by the production team. Many participants agreed that they would use the service and be willing to pay \$1/episode. Participants were less enthusiastic with the idea of downloading the conventional AD track by itself. They agreed that listening to audio only versions of television shows created by the content creation team were more entertaining. We suggest that the findings of this study seem to indicate a potential source of revenue for broadcasters while simultaneously serving as a means to better the quality of $\mathrm{AD}$ for television and film viewers. In addition, it would allow the AD process to become more equitable (principal one), as it would create an addition revenue stream for broadcasters while boosting quality and engaging more users. The marketability of AD would also provide broadcasters with more incentive to make their products simpler and more intuitive to use (principal three) by adding talking menus (see Greening \& Rolph, 2007) and other features to their products and, in doing so, further increase product desirability. 
$\mathrm{CC}$ and $\mathrm{AD}$ provide television and film audiences with alternative means to access information, as audio stimuli substitutes for video and vice versa. However, the original designer, the director, does not conceptualize, develop, create or even assess the effectiveness of the $\mathrm{CC}$ and $\mathrm{AD}$ that later becomes attached to her work. Whereas every other aspect is shaped to form parts of an inextricable and greater whole, the $\mathrm{CC}$ and $\mathrm{AD}$ exist on the outside, noticeably different parts that do not fit, as they have not been created by the same person with the same vision. Not only should the creation of CC and $\mathrm{AD}$ be left to the director, we hold that the criteria through which these assessments are made as well as the assessment itself should fall under directorial control.

\section{Conclusion}

$\mathrm{CC}$ and $\mathrm{AD}$ provide television and film audiences with alternative means to access information, as audio stimuli substitutes for video and vice versa. However, the original designer, the director, does not conceptualize, develop, create or even assess the effectiveness of the $\mathrm{CC}$ and $\mathrm{AD}$ that later becomes attached to his work. Whereas every other aspect is shaped to form parts of an inextricable and greater whole, the $\mathrm{CC}$ and $\mathrm{AD}$ exist on the outside, noticeably different parts that do not fit, as they have not been created by the same person with the same vision.

While $\mathrm{CC}$ and $\mathrm{AD}$ was established as a means to ensure equal access to entertainment, we believe that the current method through which this is achieved represents a less than ideal realization of this goal, especially by universal design and engineering theory. In effect, the current model for $\mathrm{CC}$ and $\mathrm{AD}$ kicks the original designer to the very curb he is best equipped to cut. The process that we have advocated 
here seeks to remedy some of these problems by giving television and film directors the opportunity to develop, supervise and execute their own accessibility strategies through the creation of $\mathrm{CC}$ and $\mathrm{AD}$ that fits their unique vision.

\section{Acknowledgements}

We would like to gratefully acknowledge Canadian Heritage and the Social Science and Humanities Research Council of Canada for funding this through the CulturAll project and the Community-University Research Alliances CLIME project. marblemedia generously permitted the use of Fig 1. In addition, we thank Lisa Copeland for editing this paper. 


\section{Works Cited}

Audio Description Associates (n.d.). Audio description: The visual made verbal, Retrieved April 9, 2007 from http://www.audiodescribe.com/article1.html.

Ball, W. (1984). A sense of direction. Quite Drama Book Publishers: New York.

Benedetti, R.L. (1985). The director at work. Prentice Hall: Englewood Cliffs: NJ.

Bordwell, D., \& Thompson, K. (2001). Film Art: An Introduction (6th ed.). McGraw Hill: New York.

Brosius, H.B., Donsbach, W. and Birk, M., (1996). How do text-picture relations affect the information effectiveness of television newscasts. Journal of Broadcasting \& Electronic Media, 40(2), 1980-195.

Branigan, E. (1984). Point of view in the cinema. Mouton Publishers: Berlin.

Braun, S. (2007). Audio Description from a discourse perspective: a socially relevant framework for research and training. Linguistica Antverpiensia 6. Retrieved on Aug 8, 2008 from http://epubs.surrey.ac.uk/translation/1.

Canadian Association of Broadcasters. (2004). Closed captioning standards and protocol for Canadian English Language broadcasters. Retrieved on Jan. 12, 2006 from http://www.cabacr.ca/english/social/captioning/captioning.pdf2004.

Canadian Radio-television and Telecommunications Commission. (2004). Broadcasting Public Notice CRTC 2004-2. Retrieved on Feb 7, 2007 from http://www.crtc.gc.ca/archive/ENG/Notices/2004/pb2004-2.htm

Connell, B.R., Jones, M., Mace, R., Mueller, J., Mullick, A., Ostroff, E., Sanford, E. Story, M. \& Vanderheiden, G. (1997). "The Principles of Universal Design". In Story, M.F., Mueller, J.L., \& Mace, R.L. The Universal Design File. NY State University Press: New York.

Emiliani, P. L., \& Stephanidis, C. (2000). From adaptations to user interfaces for all. Paper presented at the 6th ERCIM workshop CNR-IROE, Florence, Italy.

Erlandson, R.F. (2007) Universal and accessible design for products, services and processes. CRC Press: New York.

Fels, D.I., Branje, C. Lee, D.G. \& Hornburg, M. (2005). Emotive captioning and access to television. Proceedings of the Eleventh Americas Conference on Information Systems (AMCIS), Omaha,, p. 2330-2337 
Fels, D. I., Udo, J. P., Diamond, J. E., \& I., D. J. (2006). A comparison of alternative narrative approaches to audio description for animated comedy. Journal of Visual Impairment and Blindness, 100 (5), 295-305.

Fels, D. I., Udo, J. P., Ting, P., Diamond, J. E., \& Diamond, J. I. (2005). Odd Job Jack Described - A first person narrative approach to described video. Journal of Universal Access in the Information Society, 5(1), 73-81.

Fleischman, M. \& Roy, D. (2007). Situated Models of Meaning for Sports Video Retrieval. Proceedings of NAACL HLT 2007, Companion Volume, Rochester, p. 3740 ,

Goldman, M \& Goldman S. (1988). Reading with Closed Captioned Tv. Journal of Reading, 31(5), 458-61.

Greening, J. \& Rolph, D. (2007). Accessibility: raising awareness of audio description in the UK. In Cintas, J.D.; Orero, P.; Remael, A. (eds.) Media for all: subtitles for the Deaf, audio description and sign language. Rodophi Press: New York.

Guillory, H.G. (1998). The effects of keyword captions to authentic French video on learner comprehension. CALICO Journal, 15(1-3), 89-108.

Harkins, J.E., Korres, E., Singer, B.R., Virvan, B.M. (1995). Non-Speech Information in Captioned Video: A Consumer Opinion Study with Guidelines for the Captioning Industry. Gallaudet Research Institute.

Helander, M. (2005). A guide to human factors and ergononics, second edition. CRC Press: Boca Raton.

Hewes, D. E., Graham, M.L., Monsour, M., Doelger, J.A. (1989). Cognition and social information-gathering strategies. Human Communication Research. 16(2), 297-321.

ITC (Independent Television Commission). (1999). ITC Guidance on Standards for Subtitling. Retrieved on August 8, 2008 from http://www.itc.org.uk/codes_guidelines/broadcasting/tv/sub_sign_audio/subtitling_stn $\underline{\mathrm{ds} / ? \mathrm{a}=87101}$

ITC, 2000. ITC Guidance on Standards for Audio Description. Retrieved on August 8, 2008 from

http://www.itc.org.uk/codes_guidelines/broadcasting/tv/sub_sign_audio/audio_descript ion_stnds/?a=87101

Jensema, C.J., (1998). Viewer reaction to different television captioning speeds. American Annals of the Deaf 143(4), 318-324. 
Jordan, A.B., Albright, A., Branner, A., Sullivan, J. (2003). The state of closed captioning services in the United States. National Captioning Institute Foundation, 1-47.

Konstantinidis, B., Price, E., Diamond, J. \& Fels, D.I., (in press). Described video information and animation: A Case study of Odd Job Jack. A manuscript accepted to Journal of Social and Humanistic Computing.

Lee, D.G., Udo, JP., Fels, D.I. (2007). Enhanced captions. Computers and Entertainment 5 (2) Retrieved on Sept 3, 2008 from http://portal.acm.org/citation.cfm? $\mathrm{id}=1279540.1279551 \&$ coll=GUIDE\&dl=ACM\&idx $=\mathrm{J} 912 \&$ part $=$ magazine $\&$ WantType $=$ Magazines \& title $=\mathrm{CIE}$

Linebarger, DL. (2001). Learning to read from television: the effects of using captions and narration. Journal of Educational Psychology, 93(2), 288-98.

Packer, J. \& Kirchner, C. (1997). Who's watching? American Foundation for the Blind. Retrieved on November 15, 2007 from http/www.empowermentzone.com/watching.txt

Peli, E., \& Fine, E. M. (1996). Evaluating visual information provided by AD. Journal of Visual Impairment and Blindness, 90(5), 378-385.

Media Access Australia. (2007). Audio description. Retrieved April 12, 2007 from http://www.mediaaccess.org.au/audiodescription/c.aspx?id=35.

National Centre for Accessible Media (2003). Rich media accessibility. Retrieved Oct. 19, 2004 from http://ncam.wgbh.org/richmedia/strategies/XAD.php

Peli, E., \& Fine, E. M. (1996). Evaluating visual information provided by audio description. Journal of Visual Impairment and Blindness, 90(5), 378-385.

Rashid, R., Vy, Q., Hunt, R., Fels, D.I. (2007). Dancing with words. Proceedings of the 6th ACM SIGCHI conference on Creativity \& cognition. Retrieved on Sept 3, 2008 from http://portal.acm.org/citation.cfm?id=1254960.1255007\&jmp=cit\&coll= GUIDE \&dl=ACM\&CFID=1553729\&CFTOKEN=67805998\#CIT

Rose, D. H., \& Meyer, A. (2002). Teaching Every Student in the Digital Age. Virginia: Association for Supervision and Curriculum Development, Alexandria.

Schmeidler, E., \& Kirchner, C. (2001). Adding audio description: Does it make a difference. Journal of Visual Impairment and Blindness April, 198-212.

Sengers, P. (2003). The Engineering of experience. In Blythe, M.A., Monk, A.F., Overbeeke, K. and Wright, P.C. (eds.) Funology: From Usability to Enjoyment, 19-29. 
Shea, P. (2000). Leveling the playing field: a study of captioned interactive video for second language learning. Journal of Educational Computing Research, 22(3), 243 263.

Snyder, J. (2004). Audio Description: The visual made verbal. Retrieved on Nov. 25, 2004, from http://www.audiodescribe.com/article1.html.

Stephanidis, C. (2001). Adaptive techniques for universal access. User Modeling and User-Adapted Interaction, 11, 159-179.

Stewart, MA \& Pertusa, I. (2004). Gains to Language Learners from Viewing Target Language Closed-Captioned Films. Foreign Language Annal,s 37(1), 438-447.

Turner, J.M. and Colinet, E. (2004). Using audio description for indexing moving images. Knowledge Organization, 31(4), 222-230.

Uncredited (1985). The play's the thing. British Journal of Visual Impairment, 3(3), 9192.

U.S. Department of Justice (2003). ADA home page. Retrieved Oct. 3, 2003 from http://www.usdoj.gov/crt/ada/adahom1.htm.

Vera, J.F. (2006) Translating audio description scripts: the way forward? -Tentative first stage project results. MuTra 2006 Audio Visual Translation Scenarios: Conference proceedings. 1Copenhagen, p. 148-181.

W3C. (2003). Web content accessibility guidelines 1.0. Retrieved October 3, 2003 from http://www.w3.org/WAI/.

WGBH Educational Foundation (n.d., a) Retrieved on June 10, 2008 from http://main.wgbh.org/wgbh/pages/mag/services/captioning/faq.

WGBH Educational Foundation (n.d., b) Retrieved on June 10, 2008 from http://main.wgbh.org/wgbh/pages/mag/services/description/dvs-faq.html.

Watkins \& Charlson, 2002. Accessible Video Services for People Who Are Blind or Visually Impaired. In (Handman, G.P. (ed) Video Collection Development in Multitype Libraries. Second Edition: Westport, CT. 